\title{
Research Paper: \\ Anticipatory Electromyographic Activity and Onset Time in Selected Muscles of Lower Limb Between the Active and Inactive Old Women
}

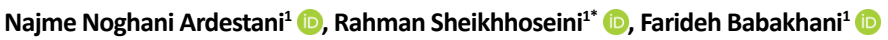

1. Department of Corrective Exercise \& Sport Injury, Faculty of Physical Education and Sport Sciences, Allameh Tabataba'ei University, Tehran, Iran.

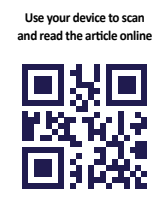

dtation Noghani Ardestani N, Sheikhhoseini R, Babakhani F. Anticipatory Electromyographic Activity and Onset Time in Selected Muscles of Lower Limb Between the Active and Inactive Old Women. Journal of Exercise Science and Medicine (JESM). 2019; 11(2):89-96. http://dx.doi.org/10.32598/JESM.11.2

dol $h$ ttp://dx.doi.org/10.32598/JESM.11.2

\section{(c) (1) (\$)}

Article info:

Received: 10 Jan 2019

Accepted: 23 May 2019

Available Online: $01 \mathrm{Jul} 2019$

Keywords:

Electromyography, Aged, Exercise, Muscles, Women

\begin{abstract}
Introduction: This study aimed to investigate the onset time and the electromyographic activity level of the selected lower limb muscles in the active and inactive old women.

Materials and Methods: In this case-control study, 28 old women with a Mean \pm SD age of $61.07 \pm 0.88$ years were selected in the inactive ( 15 people) and active ( 13 people) groups. The electrical activity of the selected muscles of the lower limbs was collected by the EMG device in a stair down movement.

Results: The onset time of tibialis anterior, vastus lateralis, and biceps femoris muscles are faster in the active group $(\mathrm{P}<0.05)$. Besides, the activity level of the rectus femoris muscle in the interval of $100 \mathrm{~ms}$ before the initial contact and the ratio of the vastus medialis muscle to the biceps femoris muscle was significantly lower $(\mathrm{P}<0.05)$ in the active group.

Conclusion: It seems that the muscles of the lower limbs in the group of women with regular physical activity are activated faster than the inactive group and the decrease in the activity of the rectus femoris muscle and the ratio of the vastus medialis to the biceps femoris muscle in the active women may be accompanied by fatigue and reduced intra-articular forces. Therefore, it is recommended that old women participate in regular and active exercise programs to improve their onset times of muscle activity.
\end{abstract}

\section{* Corresponding Author:} Rahman Sheikhhoseini, PhD.

Address: Department of Corrective Exercise \& Sport Injury, Faculty of Physical Education and Sport Sciences, Allameh Tabataba'i University, Tehran, Iran.

Tel: +98 (21) 48394134

E-mail: rahman.pt82@gmail.com 


\section{Introduction}

Iderly people, especially those with a history of falls, tend to reduce their falls by lowering their daily activities. This decrease in activity can be accompanied by a decrease in strength and an increased risk of falling [1]. Various studies have shown that active old people are at lower risk of cardiovascular death, breast and prostate cancer, fractures, recurrent falls, ADL (activities of daily living) disability, functional and cognitive impairment, dementia, Alzheimer disease, and depression. Active old people also experience healthier aging, a better quality of life, and improved cognitive function [2].

Many studies have examined the effect of various exercises on the health of old people. The positive effects of exercise in the old people include improving functional capacity and independent living, and improving the quality of life [3], increasing the speed of life activities and reducing the fear of falling, and increasing the ability to perform daily activities [4], improving dynamic balance and reaction time [5]. Exercise is also expected to improve muscle activation patterns. It has been indicated that $\mathrm{Pi}$ lates exercises can reduce involuntary muscle activity [6].

On the other hand, some studies have shown that old people with regular physical activity have less fat mass (better body composition), more hand strength, more extensor leg muscle strength, as well as better mobility, compared with the inactive old people $[7,8]$. It has also been observed that inactive old people perform poorly in walking parameters, including step length, step time, dual support ratio, as well as cognitive automation index, compared with the active old people and young people $[9,10]$.

Previous studies have shown that the pattern of muscle activity and the predictive function of postural control in old people has changed compared with that in young people [11]. Also, the muscle co-contraction ratio is higher in the elderly than in the young $[12,13]$. The cocontraction of muscles of the lower limb is an important mechanism involved in increasing postural stability during weight-bearing. It seems that more co-contraction may play a role as a compensation mechanism for poor postural control [14]. Although co-contraction may be a compensatory strategy, high levels of co-contraction in the old people may increase energy consumption and reduced efficiency during movement, increased mechanical work, increased body metabolism, and motor unit recruitment for postural control and slow motion
[15]. In old age, the pattern of walking and muscle function changes, and regular physical activity can have beneficial effects on a person's daily activities [10].

However, based on the researcher's knowledge, no study has investigated and compared the patterns of predictive and co-contractile performance of the muscles of the lower limbs in the old people in the active and inactive groups. Therefore, in this study, we seek to answer the question of whether there is a difference between the onset time and the anticipatory electromyographic activity level of the selected lower limb muscles in the active and inactive old women.

\section{Methods}

The present study is a case-control study with the ethical code IR.USWR.REC.1397.092 registered at the University of Social Welfare and Rehabilitation Sciences. In this study, 28 volunteer old women in both active and inactive groups were selected by convenience sampling method (13 in the active group and 15 in the inactive group).

To calculate the number of samples, considering $\alpha=0.05$ and $\beta=0.20$, and using the rate of EMG rise variable between two groups of the aged people with high and low physical activity [16] and using G Power 3.1.9.2 software, at least 12 people should be in each group. To prevent the risk of a possible dropout effect, we selected 14 people in each group.

The age range of participants was from 55 to 80 years, and the inclusion criterion for the active group was a history of regular exercise (two sessions per week for at least the past two years). Exclusion criteria include a clear postural disorder based on New York criteria, a history of lower limb surgery over the past year, a history of lumbopelvic operation, a history of certain diseases or any disease (neuromuscular disease, severe spinal abnormalities, polio, active infection, malignant tumors, severe vision or hearing problems) that affect a person's ability to move. Based on the level of activity, the subjects were divided into two groups, active and inactive, which finally formed 13 in the active groups and 15 in the inactive groups. Before the measurements, the subjects were given a general description of the study process, and all participants read and signed the consent form for participation in the study. At first, the height and weight of the subjects were measured and the Baecke Physical Activity Questionnaire (BPAQ) was completed. The maximum voluntary isometric contraction test of the selected muscles was performed according to the proposed SENIAM (surface EMG for non-invasive 
assessment of muscles) protocol [17]. The predictive and co-contractile functions of the selected muscles of the lower limbs were then measured by the researcher in two groups as they climbed down the $20-\mathrm{cm}$ stair.

\section{Baecke Physical Activity Questionnaire (BPAQ)}

The physical activity questionnaire was developed by Baecke et al. (1982) and its reliability was reported to be 0.73 . The validity of the instrument has been confirmed in several tests. This questionnaire consists of 16 questions and three sections: work, sports, and leisure. Together they calculate the intensity of physical activity. The reliability coefficient was obtained as 0.77 by the retest method for the physical activity questionnaire [18]. This questionnaire has been used as an auxiliary tool to ensure more accurate screening of the active elderly group.

\section{Measurement and recording EMG}

To determine the dominant foot of each subject, the subject was asked to hit the ball without giving any instructions, the foot with which the subject performed at least 2 out of 3 hits was considered as the preferential foot [19]. The EMG activity of selected lower limb muscles was recorded during the stair down. From the stance (preferential) lower limb, the tibialis anterior, vastus lateralis, vastus medialis, rectus femoris, lateral gastrocnemius, and biceps femoris muscles, and from the swing (non-preferential) lower limb, biceps femoris muscle was selected.

Surface electrodes were attached on the muscles according to the SENIAM protocol guidelines as follows: tibialis anterior muscle, in the one-third line that connects the head of the fibula to the medial malleolus; vastus lateralis muscle, in the one-third of a line that connects the Anterior-Superior Iliac Spine (ASIS) to the patellar anterior superior angle; vastus medialis muscle, the one-fifth of the line that connects the ASIS to the anterior portion of the medial collateral ligament; rectus femoris muscle, half of the line connecting the ASIS to the upper edge of the patella; lateral gastrocnemius muscle, in the one-third of the line that connects the head of the fibula to the center of the heel; biceps femoris muscle, half of a line that connects the ischial tuberosity to the lateral condyles of the tibia.

The activity of the selected muscles of the lower limbs of all subjects was recorded by a wireless electromyographic device manufactured by Baya med Company of Iran with $2000 \mathrm{~Hz}$ sampling frequency. Also, a $500-\mathrm{Hz}$ high-pass filter and a $10-\mathrm{Hz}$ low-pass filter were used to remove waste signals and possible noises. A $50-\mathrm{Hz}$ notch filter was used to remove the noise from the urban electric frequency. During the movement, the device was placed inside the belt for connecting the device to the body, and the signals were transmitted to the computer wirelessly. The Maximal Voluntary Isometric Contraction (MVIC) test was taken before the stair down to normalize the data. To record the EMG of MVIC of the muscles, the following procedure was performed:

For the tibialis anterior muscle: in a standing position with the ankle at a 90-degree angle against the resistance of the dorsiflexion;

For the quadriceps femoris muscles: the dominant leg, in a sitting position, keeps the head and trunk straight and the knee is bent at 70 to 90 degrees, and against the resistance in the leg, it is attempted to open the knee.

For the vastus medialis, vastus lateralis, and rectus femoris muscles: the subject sits on a chair and resists the force applied to flex the joint while the knee is 90 degrees.

For the lateral gastrocnemius muscle: the participant extends his knee fully and places the sole of the dominant foot on the wall. The position of the ankle is 90 degrees of dorsiflexion and the person tries to perform the plantar flexion movement [20].

For the biceps femoris muscle: the participant was lying in a prone position and, against the resistance, performs flexion and external isometric rotation of the knee at a 45-degree flexion angle.

The person held the test as an isometric test: for each muscle for 5 seconds, and a total of 3 trials with $60 \mathrm{sec}$ onds of rest intervals were repeated. The values obtained from the first and last seconds were removed and the mean of 3 seconds was used to calculate RMS [21].

The stair test ( $20 \mathrm{~cm}$ of height) was performed in such a way that the person was standing above a $20 \mathrm{~cm}$ stair (with safety precautions) and the foot switch was located on the ground at an approximate possible landing distance. The subject was asked to announce when she was ready, then descended on the foot switch with the non-preferential foot upon the command. In total, the test was repeated three times and the average value was calculated. Failure to contact the foot switch, descending on the preferential foot, and imbalance led to the repetition of the test. The time of the first contact of the swing foot with the foot switch was selected as the initial 
contact time, and the biceps femoris muscle of the swing foot was selected as the prime mover muscle to compare the onset time of stance limb with this muscle [11].

Besides, the muscle RMS was calculated in a $100-\mathrm{ms}$ interval before the initial contact. The muscle synergy ratio was obtained by dividing the RMS value of the antagonistic muscles in this period. Also, using Lab View software, the average resting time activity of each muscle was calculated. When the muscle activity of the three standard deviations exceeds the average resting time activity and lasts for $0.025 \mathrm{~s}$, it is considered as the onset time of muscle activity [23]. In the present study, to extract the onset time of muscle activity, the mean difference between the onset time of stance limb muscle activity was subtracted from the biceps femoris muscle of the swing limb.

The data of the subjects' characteristics and the research variables were analyzed in the two sections of descriptive statistics and inferential statistics in SPSS v. 25. The Shapiro-Wilk test was used to examine the normal distribution of data and the independent t-test was used to determine the difference between the study groups. The significance level for all statistical methods was considered to be less than 0.05 .

\section{Results}

Table 1 presents the means and standard deviations of age, height, weight, body mass index, and BPAQ score of the subjects. According to the results of the independent $t$-test, apart from the score of the BPAQ $(P<0.001)$, there was no significant difference between the baseline characteristics of the two groups $(P>0.05)$.

The independent t-test was used to compare the onset time of the selected muscles of the lower limbs in both active and inactive groups. The results of this test are reported in Table 2.

Table 1. Demographic characteristics of the participants and comparison between the two groups

\begin{tabular}{|c|c|c|c|c|c|c|}
\hline \multirow[b]{2}{*}{ Groups } & \multirow[b]{2}{*}{ No. } & \multicolumn{5}{|c|}{ Mean \pm SD } \\
\hline & & Age (y) & Weight (kg) & Height (cm) & $\begin{array}{c}\text { Body Mass In- } \\
\operatorname{dex}\left(\mathrm{kg} / \mathrm{m}^{2}\right)\end{array}$ & BPAQ \\
\hline Active & 13 & $59.30 \pm 2.75$ & $67.96 \pm 5.51$ & $157.61 \pm 5.79$ & $27.47 \pm 3.15$ & $8.72 \pm 1.60$ \\
\hline Inactive & 15 & $62.60 \pm 5.55$ & $69.53 \pm 11.59$ & $154.80 \pm 5.47$ & $29.02 \pm 4.81$ & $6.41 \pm 1.10$ \\
\hline \multicolumn{2}{|c|}{$\mathrm{P}$ (Independent $\mathrm{t}$-test) } & 0.064 & 0.645 & 0.198 & 0.330 & $<0.001 *$ \\
\hline
\end{tabular}

Table 2. Comparison of the onset time of the selected muscles of the lower limbs in both active and inactive groups

\begin{tabular}{|c|c|c|c|c|}
\hline Variables & Groups & Mean $\pm S D$ & Mean Diffrence & $\mathbf{P}$ \\
\hline \multirow{2}{*}{ Tibialis anterior (ms) } & Active & $-1.44 \pm 1.15$ & \multirow{2}{*}{-1.22} & \multirow{2}{*}{$0.003^{*}$} \\
\hline & Inactive & $-0.21 \pm 0.91$ & & \\
\hline \multirow{2}{*}{ Vastus laterialis (ms) } & Active & $-0.65 \pm 0.87$ & \multirow{2}{*}{-1.04} & \multirow{2}{*}{$0.001^{*}$} \\
\hline & Inactive & $0.38 \pm 0.60$ & & \\
\hline \multirow{2}{*}{ Vastus medialis (ms) } & Active & $-0.15 \pm 0.61$ & \multirow{2}{*}{-0.44} & \multirow{2}{*}{0.177} \\
\hline & Inactive & $0.28 \pm 0.91$ & & \\
\hline \multirow{2}{*}{ Rectus femoris (ms) } & Active & $-0.18 \pm 0.77$ & \multirow{2}{*}{-0.54} & \multirow{2}{*}{0.137} \\
\hline & Inactive & $0.35 \pm 1.04$ & & \\
\hline \multirow{2}{*}{ Gastrocnemius lateral (ms) } & Active & $-0.60 \pm 1.36$ & \multirow{2}{*}{-0.71} & \multirow{2}{*}{0.147} \\
\hline & Inactive & $0.10 \pm 1.15$ & & \\
\hline \multirow{2}{*}{ Biceps femoris (ms) } & Active & $-0.66 \pm 1.34$ & \multirow{2}{*}{-1.25} & \multirow{2}{*}{$0.006^{*}$} \\
\hline & Inactive & $0.59 \pm 0.84$ & & \\
\hline
\end{tabular}

*Statistically significant differences were observed. 
Table 3: Comparing the activity level of the selected muscles of the lower limbs at a time interval of $100 \mathrm{~ms}$ before the initial contact in both active and inactive groups

\begin{tabular}{|c|c|c|c|c|}
\hline Variables & Groups & Mean $\pm S D$ & Mean Diffrence & $\mathbf{P}$ \\
\hline \multirow{2}{*}{ Tibialis anterior } & Active & $2.40 \pm 1.82$ & \multirow[b]{2}{*}{0.50} & \multirow[b]{2}{*}{0.37} \\
\hline & Inactive & $1.89 \pm 1.09$ & & \\
\hline \multirow{2}{*}{ Vastus lateralis } & Active & $1.32 \pm 1.15$ & \multirow{2}{*}{-0.38} & \multirow{2}{*}{0.33} \\
\hline & Inactive & $1.70 \pm 0.80$ & & \\
\hline \multirow{2}{*}{ Vastus medialis } & Active & $1.13 \pm 0.57$ & \multirow{2}{*}{-1.58} & \multirow{2}{*}{0.15} \\
\hline & Inactive & $2.71 \pm 3.20$ & & \\
\hline \multirow{2}{*}{ Rectus femoris } & Active & $0.93 \pm 0.48$ & \multirow{2}{*}{-0.68} & \multirow{2}{*}{$0.01^{*}$} \\
\hline & Inactive & $1.61 \pm 0.73$ & & \\
\hline \multirow{2}{*}{ Gastrocnemius lateral } & Active & $1.22 \pm 1.35$ & \multirow{2}{*}{-0.08} & \multirow{2}{*}{0.83} \\
\hline & Inactive & $1.30 \pm 0.62$ & & \\
\hline \multirow{2}{*}{ Biceps femoris } & Active & $0.83 \pm 0.45$ & \multirow{2}{*}{-0.21} & \multirow{2}{*}{0.43} \\
\hline & Inactive & $1.04 \pm 0.86$ & & \\
\hline \multirow{2}{*}{ Biceps femoris (mobile foot) } & Active & $1.13 \pm 0.83$ & \multirow{2}{*}{-0.16} & \multirow{2}{*}{0.60} \\
\hline & Inactive & $1.30 \pm 0.77$ & & \\
\hline
\end{tabular}

*Statistically significant differences were observed.

Exercise Science and Medicine

Table 4. Comparing muscle co-contraction in a time interval of $100 \mathrm{~ms}$ before the initial contact in both active and inactive groups

\begin{tabular}{|c|c|c|c|c|}
\hline Variables & Groups & Mean \pm SD & Mean Diffrence & $\mathbf{P}$ \\
\hline \multirow{2}{*}{ Vastus medialis/Vastus lateralis } & Active & $0.94 \pm 0.66$ & \multirow{2}{*}{-0.83} & \multirow{2}{*}{0.18} \\
\hline & Inactive & $1.77 \pm 1.72$ & & \\
\hline \multirow{2}{*}{ Vastus lateralis/Biceps femoris } & Active & $1.74 \pm 1.35$ & \multirow{2}{*}{-0.44} & \multirow{2}{*}{0.32} \\
\hline & Inactive & $2.18 \pm 0.81$ & & \\
\hline \multirow{2}{*}{ Vastus medialis/Biceps femoris } & Active & $1.39 \pm 0.37$ & \multirow{2}{*}{-2.31} & \multirow{2}{*}{$0.03^{*}$} \\
\hline & Inactive & $3.70 \pm 3.73$ & & \\
\hline \multirow{2}{*}{ Rectus femoris/Biceps femoris } & Active & $1.42 \pm 0.83$ & \multirow{2}{*}{-0.78} & \multirow{2}{*}{0.10} \\
\hline & Inactive & $3.20 \pm 1.45$ & & \\
\hline \multirow{2}{*}{ Tibialis anterior/Gastrocnemius lateral } & Active & $3.18 \pm 2.44$ & \multirow{2}{*}{1.44} & \multirow{2}{*}{0.08} \\
\hline & Inactive & $1.73 \pm 1.06$ & & \\
\hline
\end{tabular}

*Statistically significant differences were observed.

Exercise Science and Medicine

According to Table 2, the test results between the two groups show that in the active group, the onset times of tibialis anterior muscle, vastus lateralis muscle, and biceps femoris muscle are significantly faster compared with the ones in the inactive group $(P<0.05)$.

The independent t-test was used to compare the activity level of the selected muscles of the lower limbs at a time interval of $100 \mathrm{~ms}$ before the initial contact in both active and inactive groups. The results of this test are reported in Table 3.

According to Table 3, the test results between the two groups show that in the $100 \mathrm{~ms}$ phase before the foot hits the ground, the amount of rectus femoris muscle activity $(P=0.014)$ in the active group is significantly lower than that in the inactive group.

Besides, Table 4 presents the results of the independent $t$-test to compare groups in the ratio of muscle cocontraction in a time interval of $100 \mathrm{~ms}$ before the first contact of the moving foot with the ground in both active and inactive groups.

The results of the independent t-test show that in the $100 \mathrm{~ms}$ phase before the foot hits the ground, the ratio of the activity of vastus medialis muscle to biceps femoris muscle $(P=0.038)$ in the active group is significantly lower. 


\section{Discussion}

The findings of the present study showed that in the active group, the onset times (anticipatory function) of the tibialis anterior muscle, vastus lateralis muscle, and biceps femoris muscle were faster and the ratio of the activity of rectus femoris muscle and the ratio of the activity of vastus medialis muscle to biceps femoris muscle (co-contraction ratio) was less.

The results of the present study showed that the onset times of anticipatory activity of tibialis anterior muscle, vastus lateralis muscle, and biceps femoris muscle in the active group were significantly faster than the inactive group.

The anticipatory pattern of postural control is the muscular adjustment that appears before the voluntary movement to eliminate body fluctuations during movement, maintain body stability, and minimize imbalance. The anticipation of the movement is pre-programmed in the central nervous system, relying on sensory-motor memory, and is in response to external forces that stimulate the position of the limb [22]. Before the initial foot contact, the anticipatory muscle activity begins which prepares the body to absorb the contact force and maintains the body's stability. Muscle activity before landing is a measure of anticipatory performance [23]. In the elderly, the pattern of anticipatory postural function changes, including delayed onset time in the tibialis anterior and quadriceps muscles [24]. Delay in the onset time of postural muscle activity also appears to associate with balance and motor control disturbance [25]. Improving the anticipatory function and onset time of postural muscle activity and less displacement of the center of pressure and improved postural control have been observed in the old people after a period of exercise training [26]. Because regular skeletal muscle activity is associated with improved performance in old age, it may be a safe and effective way to increase proper integration between the central and peripheral nervous systems and improve performance in old age [27]. Jagdhane et al. found that a 4-week training program based on an anticipatory mechanism could be effective in improving postural control, functional balance, mobility, and quality of life in the old people [28].

Another finding of this study showed that the activity level of the rectus femoris muscle and the ratio of the activity of the vastus medialis to the biceps femoris muscle (co-contraction ratio) in the active group is low. Research findings show that older people have higher muscle co-contraction than younger people. Previous studies investigated this issue on active young and elderly people with low risk of falls $[12,29]$ have shown that old people use their thigh muscles more often when walking in a state of sudden disturbance. Also, they have more co-contraction in the knee and ankle joints. A recent study compared co-contraction ratios between healthy youth and the elderly in three situations: walking, climbing, and descending stairs. The results showed that the old subjects had $18 \%-22 \%$ more knee co-contractions when performing stair task steps, as well as $17 \%-29 \%$ more knee co-contractions during the swing phase [13]. Old people may subconsciously use co-contraction to prepare the joint for postural control [14]. Although co-contraction may be a compensatory strategy to control poor posture, the high levels of co-contraction in the old people may lead to increased energy consumption and reduced efficiency during movement, increased mechanical work, increased body metabolism, and higher motor units recruitment for postural control [15].

It seems that constant co-contraction leads to increased joint compressive forces and the progression of osteoarthritis [30]. Moreover, it is shown that although co-contraction stabilizes the joint while standing, it reduces the ability for dynamic postural control [31]. On the other hand, research shows that regular physical activity and exercise may reduce co-contraction. It has been shown that balance exercises can reduce muscle co-contraction during dynamic postural control in the elderly $[10,32,33]$. The results of the present study were consistent with the results of previous studies. So that in the active group, less co-contraction was observed in the knee joint of the old people.

Considering that in the current study, the lower ratio of vastus medialis to biceps femoris muscle activity was observed in the active old group, training may improve the neuromuscular coordination in the central nervous system and reduce co-contraction. Training and exercise facilitate performing the movements by adjusting and improving the muscle activity onset time or muscle activity co-contraction.

The results of this study can be criticized from the following perspectives. Despite the role that the deep lumbopelvic stabilizer muscles play in maintaining the stability of the body, they were not examined in the study. Besides, it is better to examine such activities as climbing the stairs and even walking which are functional tasks of daily living. This research had a case-control design so it should be considered to investigate the ex- 
ercise training effect on the study variables; it is better to use interventional studies.

\section{Conclusion}

The muscles of the lower limbs in the group of women with regular physical activity are activated faster than the inactive group and the decrease in the activity of the rectus femoris muscle and the ratio of the vastus medialis to the biceps femoris muscle in the active women may be accompanied by fatigue and reduced intra-articular forces. Therefore, it is recommended that old women participate in regular and active exercise programs to improve their onset times of muscle activity.

\section{Ethical Considerations}

\section{Compliance with ethical guidelines}

All research processes and methods have been approved by the Ethics Committee in the Research of the University of Social Welfare and Rehabilitation Sciences (Code: IR.USWR.REC.1397.092).

\section{Funding}

The present paper was extracted from the MA. thesis of the first author at Department of Sports Injuries and Corrective Exercises, Faculty of Physical Education and Sports Sciences, Allameh Tabatabai University.

\section{Authors' contributions}

All authors equally contributed to preparing this article.

\section{Conflict of interest}

The authors declared no conflict of interest.

\section{References}

[1] Jefferis BJ, Iliffe S, Kendrick D, Kerse N, Trost S, Lennon LT, et al. How are falls and fear of falling associated with objectively measured physical activity in a cohort of community-dwelling older men? BMC Geriatrics. 2014; 14(1):114. [DOI:10.1186/1471-2318-14-114] [PMID] [PMCID]

[2] Cunningham C, O'Sullivan R, Caserotti P, Tully MA. Consequences of physical inactivity in older adults: A systematic review of reviews and meta-analyses. Scandinavian Journal of Medicine \& Science in Sports. 2020; 30(5):816-27. [DOI:10.1111/sms.13616] [PMID]
[3] Shaikh AA, Dandekar SP. Perceived Benefits and barriers to exercise among physically active and non-active elderly people. Disability, CBR \& Inclusive Development. 2019; 30(2):73-83.[DOI:10.5463/ dcid.v30i2.839]

[4] Pérez VS, Haas AN, Wolff SS. Analysis of activities in the daily lives of older adults exposed to the pilates method. Journal of Bodywork and Movement Therapies. 2014; 18(3):326-31. [DOI:10.1016/j. jbmt.2013.10.004] [PMID]

[5] Irez GB, Ozdemir RA, Evin R, Irez SG, Korkusuz F. Integrating Pilates exercise into an exercise program for +65 year-old women to reduce falls. Journal of Sports Science \& Medicine. 2011; 10(1):105-11. [PMCID] [PMID]

[6] de Siqueira Rodrigues BG, Cader SA, Torres NV, de Oliveira EM, Dantas EH. Pilates method in personal autonomy, static balance and quality of life of elderly females. Journal of Bodywork and Movement Therapies. 2010; 14(2):195-202. [DOI:10.1016/j. jbmt.2009.12.005] [PMID]

[7] Rava A, Pihlak A, Ereline J, Gapeyeva H, Kums T, Purge P, et al. Body composition, neuromuscular performance, and mobility: Comparison between regularly exercising and inactive older women. Journal of Aging and Physical Activity. 2017;25(1):58-64.[DOI:10.1123/ japa.2016-0019] [PMID]

[8] de Moura TG, de Almeida Nagata C, Garcia PA. The influence of isokinetic peak torque and muscular power on the functional performance of active and inactive community-dwelling elderly: A cross-sectional study. Brazilian journal of physical therapy. 2020; 24(3):256-63. [DOI:10.1016/j.bjpt.2019.03.003] [PMID] [PMCID]

[9] Kovacs E, Simon A, Petridisz AN, Erdős RL, Rozs F, Virág A. Gait parameters in physically active and inactive elderly as well as young community-living people. The Journal of Sports Medicine and Physical Fitness. 2018; 59(7):1162-7. [DOI:10.23736/S00224707.18.09205-8] [PMID]

[10] Lelard T, Doutrellot PL, Temfemo A, Ahmaidi S. Electromyographic pattern during gait initiation differentiates yoga practitioners among physically active older subjects. Frontiers in Human Neuroscience. 2017; 11:300. [DOI:10.3389/fnhum.2017.00300] [PMID] [PMCID]

[11] Shumway-Cook A, Woollacott MH. Motor control: Translating research into clinical practice. $4^{\text {th }}$ ed. Philadelphia: Wolters Kluwer Health/Lippincott Williams \& Wilkins; 2012. https://www.google com/books/edition/Motor_Control/vwofkgAACAAJ?hl=en

[12] Hallal CZ, Marques NR, Spinoso DH, Vieira ER, Gonçalves M. Electromyographic patterns of lower limb muscles during apprehensive gait in younger and older female adults. Journal of Electromyography and Kinesiology. 2013; 23(5):1145-9.[DOI:10.1016/j.jelekin.2013.06.006] [PMID]

[13] Chandran VD, Calalo JA, Dixon PC, Dennerlein JT, Schiffman JM, Pal S. Knee muscle co-contractions are greater in old compared to young adults during walking and stair use. Gait \& Posture. 2019; 73:315-22. [DOI:10.1016/j.gaitpost.2019.07.501] [PMID]

[14] Benjuya N, Melzer I, Kaplanski J. Aging-induced shifts from a reliance on sensory input to muscle cocontraction during balanced standing. The Journals of Gerontology Series A: Biological Sciences and Medical Sciences. 2004; 59(2):M166-71.[DOI:10.1093/ gerona/59.2.M166] [PMID]

[15] Mian OS, Thom JM, Ardigò LP, Narici MV, Minetti AE. Metabolic cost, mechanical work, and efficiency during walking in young and older men. Acta Physiologica. 2006; 186(2):127-39. [DOI:10.1111/ j.1748-1716.2006.01522.x] [PMID] 
[16] Laroche DP, Knight CA, Dickie JL, Lussier MÉ, Roy SJ. Explosive force and fractionated reaction time in elderly low-and high-active women. Medicine and Science in Sports and Exercise. 2007; 39(9):1659-65. [DOI:10.1249/mss.0b013e318074ccd9] [PMID]

[17] Hanada EY, Hubley-Kozey CL, McKeon MD, Gordon SA. The feasibility of measuring the activation of the trunk muscles in healthy older adults during trunk stability exercises. BMC geriatrics. 2008; 8(1):33. [DOI:10.1186/1471-2318-8-33] [PMID] [PMCID]

[18] Carvalho FA, Morelhão PK, Franco MR, Maher CG, Smeets RJ, Oliveira $\mathrm{CB}$, Júnior IF, Pinto RZ. Reliability and validity of two multidimensional self-reported physical activity questionnaires in people with chronic low back pain. Musculoskeletal Science and Practice. 2017; 27:65-70. [DOI:10.1016/j.msksp.2016.12.014] [PMID]

[19] van Melick N, Meddeler BM, Hoogeboom TJ, Nijhuis-van der Sanden MW, van Cingel RE. How to determine leg dominance: The agreement between self-reported and observed performance in healthy adults. PloS One. 2017; 12(12):e0189876. [DOI:10.1371/ journal.pone.0189876] [PMID] [PMCID]

[20] Siao P, Cros D, Vucic S. Practical approach to electromyography: An illustrated guide for clinicians. New York City: Springer Publishing Company; 2011. https://www.google.com/books/ edition/Practical_Approach_to_Electromyography/-GQT7yU$77 c C$ ?hl=en\&gbpv $=0$

[21] Lee SY, Jo ME. Comparison of maximum voluntary isometric contraction of the biceps on various posture and respiration conditions for normalization of electromyography data. Journal of Physical Therapy Science. 2016; 28(11):3007-10. [DOI:10.1589/ jpts.28.3007] [PMID] [PMCID]

[22] Jesunathadas M, Aidoor SS, Keenan KG, Farina D, Enoka RM Influence of amplitude cancellation on the accuracy of determining the onset of muscle activity from the surface electromyogram. Journal of Electromyography and Kinesiology. 2012; 22(3):494-500. [DOI:10.1016/j.jelekin.2012.01.011] [PMID] [PMCID]

[23] Aruin AS. Enhancing anticipatory postural adjustments: a novel approach to balance rehabilitation. Journal of Novel Physiotherapies. 2016; 6(2):e144. [DOI:10.4172/2165-7025.1000e144] [PMID] [PMCID]

[24] Santello M. Review of motor control mechanisms underlying impact absorption from falls. Gait \& Posture. 2005; 21(1):85-94. [DOI:10.1016/j.gaitpost.2004.01.005] [PMID]

[25] Maranesi E, Fioretti S, Ghetti GG, Rabini RA, Burattini L, Mercante $\mathrm{O}$, et al. The surface electromyographic evaluation of the Functional Reach in elderly subjects. Journal of Electromyography and Kinesiology. 2016; 26:102-10. [DOI:10.1016/j.jelekin.2015.12.002] [PMID]

[26] Aruin AS, Kanekar N, Lee YJ, Ganesan M. Enhancement of anticipatory postural adjustments in older adults as a result of a single session of ball throwing exercise. Experimental Brain Research 2015; 233(2):649-55. [DOI:10.1007/s00221-014-4144-1] [PMID]

[27] Zhorne R, Dudley-Javoroski S, Shields RK. Skeletal muscle activity and CNS neuro-plasticity. Neural regeneration Research. 2016; 11(1):69-70. [DOI:10.4103/1673-5374.169623] [PMID] [PMCID]

[28] Jagdhane S, Kanekar N, S Aruin A. The effect of a four-week balance training program on anticipatory postural adjustments in older adults: A pilot feasibility study. Current aging science. 2016; 9(4):295300. [DOI:10.2174/1874609809666160413113443] [PMID]

[29] Hallal CZ, Marques NR, Vieira ER, Brunt D, Spinoso DH, Castro $A$, et al. Lower limb muscle coactivation levels in healthy younger and older adults during functional dual-task gait. Motriz: Revista de Educação Física. 2013; 19(3):620-6. [DOI:10.1590/S198065742013000300013]

[30] Tsai LC, McLean S, Colletti PM, Powers CM. Greater muscle cocontraction results in increased tibiofemoral compressive forces in females who have undergone anterior cruciate ligament reconstruction. Journal of Orthopaedic Research. 2012; 30(12):2007-14. [DOI:10.1002/jor.22176] [PMID]

[31] Nagai K, Yamada M, Mori S, Tanaka B, Uemura K, Aoyama T, Ichihashi $\mathrm{N}$, Tsuboyama T. Effect of the muscle coactivation during quiet standing on dynamic postural control in older adults. Archives of Gerontology and Geriatrics. 2013; 56(1):129-33. [DOI:10.1016/j. archger.2012.08.009] [PMID]

[32] Nagai K, Yamada M, Tanaka B, Uemura K, Mori S, Aoyama T, Ichihashi N, Tsuboyama T. Effects of balance training on muscle coactivation during postural control in older adults: A randomized controlled trial. Journals of Gerontology Series A: Biomedical Sciences and Medical Sciences. 2012; 67(8):882-9. [DOI:10.1093/gerona/ glr252] [PMID]

[33] Kitatani R, Ohata K, Sakuma K, Aga Y, Yamakami N, Hashiguchi Y, et al. Ankle muscle coactivation during gait is decreased immediately after anterior weight shift practice in adults after stroke. Gait \& Posture. 2016; 45:35-40. [DOI:10.1016/j.gaitpost.2016.01.006] [PMID] 